\title{
A participação de alunos com síndrome de Down nas aulas de Educação Física Escolar: Um estudo de caso
}

\author{
Maria Luíza Tanure Alves* \\ Edison Duarte ${ }^{* *}$
}

\begin{abstract}
Resumo: O objetivo do estudo foi observar a realidade da inclusão da criança com síndrome de Down (SD) nas aulas de educação física escolar, identificando os obstáculos e facilidades encontrados pela mesma. Foi realizada a observação sistemática das aulas de educação física durante todo 0 ano letivo. Participaram da pesquisa 33 alunos da terceira série (20 meninos e 13 meninas) sem deficiência e um aluno com SD do sexo masculino com nove anos de idade. $O$ aluno com SD apresentou dificuldades para participar socialmente junto à turma, embora não apresentasse dificuldades para compreensão e execução das atividades propostas em aula.
\end{abstract}

Palavras-chave: Síndrome de Down. Educação Física. Equidade. Aulas.

\section{INTRODUÇÃO}

No âmbito educacional, o movimento de inclusão defende que a criança com deficiência deve ser incluída no ensino regular para que possa se desenvolver e participar ativamente da sociedade (ODOM; DIAMOND, 1998; PLACE; HOGDE, 2001; HUTZLER et al, 2002; PIVIK; MCCOMAS; LAFLAME, 2002). Seu processo educacional deve respeitar suas diferenças e atender suas

\footnotetext{
'Departamento de Atividade Física Adaptada. Faculdade de educação Física. UNICAMP. Campinas, SP, Brasil. E-mail: luizatanure@gmail.com

"Departamento de Atividade Física Adaptada. Faculdade de educação Física. UNICAMP. Campinas, SP, Brasil. E-mail: edison@fef.unicamp.br
} 
necessidades educacionais como um todo, permitindo que a mesma seja um membro ativo dentro de sua escola (ODOM; DIAMOND, 1998; PLACE; HODGE, 2001; KODISH et al, 2006).

O processo de inclusão do aluno com deficiência deve ser uma preocupação constante de seu professor. Este deve estar atento não apenas em propiciar sua participação e execução nas atividades propostas, mas também em promover a inclusão deste na rede social presente durante as aulas (ODOM; DIAMOND, 1998; PLACE; HODGE, 2001; PIVIK; MCCOMAS; LAFLAME, 2002). Desta forma, a inclusão escolar não diz respeito somente à oportunidade em desempenhar as atividades propostas pelo professor em sala, mas também em participar e estruturar uma rede de relações sociais junto aos seus colegas de classe. A participação efetiva defendida pelo movimento inclusivo deve ir além dos conteúdos propostos e abranger a inclusão social da criança em seu ambiente.

Nesse sentido, a legislação brasileira vigente garante ao aluno com deficiência o direito à inclusão no sistema regular de ensino, com atendimento especializado as suas necessidades educacionais (ALVES; DUARTE, 2011). Inicialmente, o delineamento da Declaração de Salamanca (BRASIL, 1994) durante a Conferência Mundial sobre Necessidades Educativas Especiais em Salamanca, (Espanha, 1994), traz um conjunto de diretrizes para a implantação e o direcionamento das práticas inclusivas na escola. A Declaração de Salamanca (BRASIL, 1994, p.3) proclama que:

[...] as escolas deveriam acomodar todas as crianças independentemente de suas condições físicas, intelectuais, sociais, emocionais, lingüísticas ou outras. Elas deveriam incluir crianças deficientes e superdotadas, crianças de rua e que trabalham, crianças de origem remota ou de população nômade, crianças pertencentes a minorias lingüísticas, étnicas ou culturais, e crianças de outros grupos desvantajados ou marginalizados.

O documento ainda define que o termo "necessidades educacionais especiais" refere-se a todas aquelas "[...] crianças ou jovens cujas necessidades educacionais especiais se originam em 
função de deficiências ou dificuldades de aprendizagem."(BRASIL, 1994, p.3). Ainda no âmbito do direito ao acesso à educação inclusiva, o Decreto Legislativo 186/08 (BRASIL, 2008a, p.14) que aprova o texto da Convenção sobre os Direitos das Pessoas com Deficiência e de seu protocolo facultativo (promulgada pela Assembléia-Geral das Nações Unidas, ONU, em 2006), afirma que as "[...] pessoas com deficiência devem ter acesso ao sistema fundamental de ensino, de qualidade e gratuito, em igualdade de condições com as demais pessoas nas comunidades em que vivem". A Convenção sobre os direitos das pessoas com deficiência define que pessoas com deficiência "[...] são aquelas que têm impedimentos de natureza física, intelectual ou sensorial, os quais, em interação com diversas barreiras, podem obstruir sua participação plena e efetiva, na sociedade com as demais pessoas" (BRASIL, 2008a, p. 3).

Aliado ao decreto Legislativo 186/08, a Política Nacional de Educação Especial na Perspectiva da Educação Inclusiva (BRASIL, 200b) afirma que a educação especial faz parte da proposta pedagógica da escola, e tem como público-alvo além dos alunos com deficiência, também aqueles com transtornos globais do desenvolvimento e alunos com altas habilidades/superdotação. O referido documento define:

[...] alunos com deficiência àqueles que têm impedimentos de longo prazo, de natureza física, mental, intelectual ou sensorial, que em interação com diversas barreiras podem ter restringida sua participação plena e efetiva na escola e na sociedade. Os alunos com transtornos globais do desenvolvimento são aqueles que apresentam alterações qualitativas das interações sociais recíprocas e na comunicação, um repertório de interesses e atividades restrito, estereotipado e repetitivo. Incluem-se nesse grupo alunos com autismo, síndromes do espectro do autismo e psicose infantil. Alunos com altas habilidades/ superdotação demonstram potencial elevado em qualquer uma das seguintes áreas, isoladas ou combinadas: intelectual, acadêmica, liderança, psicomotricidade e artes (BRASIL..., 2008b, p.15). 
Para Place e Hodge (2001), os benefícios do processo inclusivo são possíveis desde que ocorram as adaptações necessárias. As mudanças devem ocorrer na acessibilidade do aluno à escola e seus ambientes, nas atitudes negativas e falta de conhecimento presentes nas pessoas envolvidas como professores e funcionários, e na formulação de políticas públicas voltadas para o incentivo ao processo inclusivo (PIVIK; MCCOMAS, 2002). O estudo das barreiras encontradas pelo aluno com deficiência deve ter como foco a opinião do próprio aluno e de seus pais (GOODWIN; WATKINSON, 2000; COOK; SWAIN; FRENCH, 2001; PIVIK; MCCOMAS, 2002; HUTZLER et al, 2002).

A ausência de participação efetiva deve-se principalmente a falta de suporte dos professores, equipamentos apropriados, reduzido engajamento dos colegas de classe e obstáculos impostos pelo espaço físico (GOODWIN; WATKINSON, 2000; PIVIK; MCCOMAS, 2002). A não participação nas aulas de educação física acarreta ao aluno efeitos negativos, como a ausência de senso de pertencimento ao grupo. Para o aluno com deficiência, as experiências positivas nas aulas de educação física ocorrem quando há o senso de pertencimento ao grupo, participação total e possibilidade de benefício com o programa de atividades propostas (GOODWIN; WATKINSON, 2000).

Batista e Enumo (2004) relatam que alunos com deficiência intelectual apresentam relações sociais limitadas com seus colegas de classe. Os autores realizaram estudo sobre as interações sociais da criança com deficiência intelectual na escola para análise dos possíveis benefícios do contato social proporcionados pela escola inclusiva. Como resultado, os referidos alunos não foram totalmente aceitos por seus pares, indicando baixa freqüência de aceitação e maior nível de rejeição pelos colegas. Os alunos com deficiência intelectual foram incluídos fisicamente no ambiente, porém sem estabelecimento de vínculos sociais. A simples inserção do aluno com deficiência no ambiente não garante a ele a construção de relações sociais, bem como seus possíveis benefícios. Em outro estudo realizado com crianças com deficiência intelectual com 
objetivo de caracterizar as relações instituídas entre os alunos na aula de educação física, Ellis, Wright e Cronis (1996) descrevem resultados semelhantes como a reduzida interação desses alunos com seus pares durante as aulas de educação física. Entretanto, os autores afirmam que as interações observadas ocorreram em maior parte durante o período de tempo livre de aula, onde as atividades e associações entre colegas eram livremente escolhidas.

Em estudo realizado por Hutzler et al (2002), a inclusão estava relacionada com o tipo de interação social vivenciada, onde estas podem propiciar ou limitar a inclusão do aluno com deficiência nas aulas de educação física. As relações sociais que tinham caráter de suporte e aceitação social eram capazes de promover a inclusão enquanto que relações sociais onde estes eram ridicularizados ou ignorados causavam a exclusão do aluno com deficiência. Os autores realizaram o estudo sobre experiências de alunos com deficiência física (9 a 15 anos de idade) nas aulas de educação física para identificar os fatores colaboradores e limitantes para inclusão e empowerment.

Já em estudo realizado por Goodwin e Watkinson (2000) a inclusão nas aulas de educação física estava vinculada com experiências positivas e negativas. Experiências positivas de inclusão consistiam na formação de um senso de pertencimento, na chance de se beneficiar com o programa de atividades, e oportunidade de participar nas atividades junto com seus colegas de classe. As experiências negativas tinham características de isolamento social, sentir-se diferente devido à deficiência, ou participação limitada nas atividades. $\mathrm{O}$ isolamento social estava associado com rejeição, negligencia ou ser alvo de curiosidade pelos colegas de classe. Os alunos também tinham sua capacidade de execução das atividades questionada pelos colegas (GOODWIN; WATKINSON, 2000).

No que diz respeito à aprendizagem dos conteúdos da educação física pelos alunos com deficiência, Block e Obrusnikova (2007) relatam que esses alunos apresentam prejuízo em seu desempenho motor durante as atividades. Esse prejuízo pode ser causado pela falta de adaptações por parte dos professores no currículo, 
equipamentos ou método de ensino. A ausência das adaptações necessárias pode provocar no aluno a vivência de experiências negativas durante as aulas de educação física.

A necessidade de adaptação das aulas de educação física as capacidades do aluno com deficiência também é descrita por Blinde e McCallister (1998); Hutzler et al (2002), Place e Hodge (2001). $\mathrm{O}$ atendimento as necessidades do aluno com deficiência pressupõe formação profissional de qualidade, não apenas para os professores da disciplina, mas para todos os que trabalham na escola. Sentir-se incluído ultrapassa as barreiras da sala de aula, sendo necessário que o aluno tenha atendida e reconhecida suas necessidades em todo o ambiente escolar.

Klavina e Kudlacek (2011) descrevem que no contex to europeu os professores não se sentem preparados e capacitados para ensinar alunos com deficiência nas aulas de educação física. Os professores de educação física atuantes na região da União Européia relatam falta de suporte e serviços para atender as necessidades de seus alunos com deficiência. Desta forma, a falta de preparação profissional não é um obstáculo presente apenas na realidade educacional brasileira.

Leonardo, Bray e Rossato (2009) descrevem que as escolas públicas e privadas brasileiras tem realizado apenas a alterações no espaço físico para o recebimento do aluno com deficiência. Não há qualquer tipo de planejamento pedagógico para receber este aluno. A ausência de capacitação profissional e infraestrutura escolar são as maiores dificuldades vivenciadas pelos professores de educação física brasileiros para a inclusão. Estes afirmam possuir pouco ou nenhum conhecimento sobre os tipos de deficiências dos seus alunos (LEONARDO; BRAY; ROSSATO, 2009).

Esse estudo tem como objetivo principal observar a realidade do processo inclusivo da criança com síndrome de Down (SD) nas aulas de educação física escolar, identificando os possíveis obstáculos e facilidades encontrados pela mesma. Para tanto, pretende-se observar o processo inclusivo do aluno com SD através de seu 
envolvimento e participação efetiva nos diversos conteúdos e atividades oferecidas nas aulas de educação física escolar, bem como seu envolvimento social com seus pares.

\section{Método}

A pesquisa foi realizada através de um estudo de caso. Para a análise do processo inclusivo dos alunos com SD no ensino fundamental foi empregada a observação sistemática das aulas de educação física. Antes da caracterização do estudo, é importante salientar que a coleta de dados foi precedida por um estudo piloto com finalidade de ajustar e avaliar os instrumentos de medida. $\mathrm{O}$ estudo foi submetido e aprovado pelo Comitê de Ética da Universidade Estadual de Campinas - UNICAMP com o protocolo número 140/2007.

\subsection{AmBIENTE}

A pesquisa foi realizada em uma escola pública estadual situada no município de Campinas, São Paulo, Brasil. A referida unidade escolar é composta por turmas de $1^{\circ}$. a $4^{\circ}$. séries do ensino fundamental no período matutino e vespertino. As crianças com deficiência e matriculadas na unidade escolar podem freqüentar, no período oposto ao de seu turno de aula, salas de recurso que tem como objetivo servir como apoio para o processo de aprendizagem da criança.

Dessa forma, as crianças com deficiência frequentam o ensino regular com seus pares e assim participam também das aulas de educação física. As aulas de educação física escolar ocorreram durante o mesmo período de aula, com frequiência de duas vezes por semana e duração de cinquenta minutos. As aulas eram realizadas em uma quadra externa ao prédio escolar ou dentro da sala de aula. Os materiais necessários para execução das atividades eram fornecidos pela diretoria da escola, e eram em sua maioria bolas, cordas e cones. Grande parte das atividades não exigia material para sua execução. O conteúdo trabalhado na disciplina de educação 
física era dividido em quatro bimestres. Os temas abordados durante todo o ano foram os jogos, brincadeiras folclóricas, lutas, ginástica, jogos pré-desportivos e ritmo.

\subsection{PARTICIPANTES}

Foi selecionado como sujeito, o aluno com SD independente da limitação apresentada pela mesma. Como critério de inclusão no estudo, o aluno com SD deveria ter uma frequiência mínima de 75\% nas aulas de educação física. Para análise da inclusão do aluno com SD foi necessária a participação como sujeito da pesquisa de todos os alunos da classe do aluno com SD participante. Desta forma, apesar do estudo ter como foco apenas o aluno com SD, foi necessária a participação como sujeitos de pesquisa de todos os alunos da sua aula de educação física. $\mathrm{O}$ estudo contou com a participação de sujeitos de uma classe do ensino fundamental, $3^{\circ}$. série, a qual apresentava um aluno com SD. O aluno com SD apresentou diagnóstico médico devidamente qualificado para participação no estudo. Ao todo participaram da pesquisa 33 alunos da $3^{\circ}$. série (20 meninos e 13 meninas; 9,2 \pm 0,61 anos). O aluno com SD é do sexo masculino e tinha 9 anos de idade. Todos os participantes da pesquisa apresentaram a autorização de seus pais ou responsáveis através da assinatura do termo de consentimento e livre esclarecimento.

\subsection{ColetA DE DADOS}

Com a inclusão do aluno com SD como foco de estudo, as observações foram realizadas no contexto das aulas de educação física com a participação de todos os alunos da classe. As observações foram realizadas de forma direta e não participante pelo próprio pesquisador durante todo o ano letivo. Estas tinham como meta o aluno com SD, porém a observação da sua interação com seus pares é fundamental para análise do seu processo inclusivo. O pesquisador acompanhou semanalmente a aula de educação física, a qual tinha duração de cinquenta minutos. Não foram empregados equipamentos de vídeo para coleta de dados. 
O contexto das aulas foi observado sob três aspectos: 1) compreensão e a execução das atividades propostas; 2) a relação do aluno com seus pares e com a professora; e 3) sua relação com ambiente de aula. Para tanto, as observações seguiram um roteiro pré-estruturado com três categorias principais: atividades, relações pessoais e o ambiente (Quadro 1). Durante a observação das aulas de educação física, o comportamento do aluno com SD era classificada e registrada nas categorias citadas.

Quadro 1 - Ficha de Observação Sistemática

1.ATIVIDADES
1. ComSERVAÇÃO
2. Execução;
3. Interesse pela atividade;
4. Reprodução da atividade em tempo livre;
5. Dificuldade ou facilidade com material utilizado na atividade.
2.RELAÇÕES PESSOAIS
1. Colegas de classe
a. Interação iniciada pela criança com deficiência
b. Interação iniciada por criança sem deficiência
c. Envolvimento em atividade com colega
2. Professora de educação física
a. Ajuda e atenção ao aluno com deficiência
b. Demonstração de respeito, simpatia e confiança pela professora
3. AMBIENTE
1. Dificuldade em locomoção no espaço
2. Dificuldade em utilização do espaço

A observação das aulas de educação física sob o ponto de vista das atividades propostas teve como meta avaliar a compreensão e execução das mesmas pelo aluno com SD. Dentro deste aspecto, os autores observaram: 1) se o aluno com SD compreendia a atividade e suas dúvidas; 2) a execução da atividade de acordo com as instruções recebidas; 3) interesse do aluno pela atividade; 4) execução da atividade do tempo livre de aula. Como pontos positivos eram considerados a compreensão da atividade e sua execução (as 
dúvidas apresentadas deveriam ser totalmente elucidadas pelo professor). Os pontos negativos eram a não compreensão ou execução da atividade, bem como manifestação de dúvidas sem resposta pelo professor.

A análise observacional das relações construídas com os colegas e a professora procurou analisar a capacidade do aluno em se relacionar com sua turma e a professora, buscando os tipos de trocas estruturadas, bem como a reciprocidade encontrada. Neste ponto buscou-se avaliar 1) quem iniciava os contatos mantidos pelo aluno com SD; 2) com quais companheiros estes contatos eram mantidos; e 3) qual a natureza destes contatos. Contatos de natureza positiva eram aqueles com reciprocidade de resposta, independente de quem o iniciava. Contatos negativos eram os caracterizados por comportamentos agressivos (física ou verbalmente) e/ou sem reciprocidade de resposta.

A relação do aluno com o ambiente de aula e escolar teve como objetivo analisar a locomoção e utilização do espaço das aulas de educação física. Os autores tinham como meta avaliar 1) locomoção do aluno no espaço de aula; 2) uso dos espaços comuns como banheiros e bebedouros. Como pontos positivos eram considerados os comportamentos sociais de autonomia e independência do aluno com SD. Os pontos negativos eram considerados como necessidade de ajuda para locomoção e utilização dos espaços.

Após a observação das aulas de educação física de acordo com os aspectos mencionados, o conteúdo observado foi analisado de acordo com as categorias pré-estabelecidas: 1) atividades, 2) relações pessoais, e 3) ambiente. A separação dos dados coletados nestas categorias teve como meta principal abranger o processo inclusivo como um todo, permitindo melhor compreensão dos resultados encontrados. Cada categoria foi então analisada por conteúdo para identificar os pontos positivos e negativos vivenciados pelo aluno com deficiência durante sua inclusão nas aulas de educação física. 


\section{Resultados}

Os resultados encontrados serão apresentados de acordo com as categorias utilizadas no roteiro observacional para sua melhor compreensão.

Atividades

Com relação à compreensão e execução das atividades, todos os sujeitos apresentam boa compreensão e execução dos conteúdos e atividades propostas em aula. O aluno com SD não demonstrou dificuldade para compreensão e execução das atividades de acordo com as instruções recebidas. $\mathrm{O}$ aluno com SD conseguiu exercer os diversos papéis exigidos durante as atividades, não apresentando comportamentos de queixa ou reclamação sobre a aula. Também não houve manifestação ou demonstração de dificuldades com os materiais utilizados.

As atividades executadas permitiram a participação do aluno com deficiência em igualdade com seus pares. O aluno com SD apresentou participação efetiva em todas as aulas em que esteve presente. A participação efetiva foi considerada quando o aluno com SD se engajava nas atividades propostas pela professora, de forma a atingir os objetivos propostos. Não foram necessárias modificações em regras, nível de dificuldade ou até mesmo estrutura dos conteúdos para sua execução pelo mesmo.

Quanto ao interesse pelas atividades, o aluno com SD demonstrou interesse em participar em todas as atividades propostas em aula. No entanto, nos períodos de tempo livre o aluno com SD demonstrou baixa interação junto à turma. Para este período a professora propunha que os alunos escolhessem livremente as atividades e os colegas com quem iriam se envolver. Estes ocorreram sempre ao final da aula ou durante toda a aula em dias específicos planejados anteriormente com a turma. Em todos estes períodos de livre associação o sujeito com SD não manifestou interesse em propor atividades aos colegas, ou até mesmo em participar nas atividades propostas por estes. Durante o tempo livre o aluno apenas observava o restante da turma. 


\subsection{Relações Pessoais}

As relações sociais construídas pelo aluno com SD durante as aulas foram reduzidas. Este apresentou um número reduzido de interações com seus pares, as quais ocorreram principalmente durante a execução das atividades propostas pela professora e apenas com os colegas próximos. Apesar do número reduzido de interações, o mesmo não demonstrou dificuldade de interação com os colegas.

Como o aluno com SD já havia cursado séries anteriores com a mesma turma, seus colegas já demonstravam conhecimento das necessidades, limitações e capacidades do colega. Neste ponto, os colegas de classe não demonstravam qualquer comportamento preconceituoso ou de repulsa quanto ao aluno com SD. Apesar dessa ausência de preconceito, o mesmo era visto com indiferença por seus pares.

Durante o tempo livre das aulas, o aluno com SD não buscava estabelecer relações de troca com os colegas. Este não iniciava conversações ou trocas durante o tempo livre, e também não era procurado pelos colegas. Durante este período, o mesmo contentavase em observar os colegas e suas atividades. Os métodos aqui aplicados não permitem a investigação dos motivos apresentados pela criança com SD para tal atitude.

De maneira geral, o aluno com SD demonstrava sentimentos de carinho e respeito pela professora, procurando-a para sanar suas dúvidas durante as atividades e para mostrar suas capacidades. A professora procurou trabalhar as relações de troca entre os alunos com a utilização dos jogos cooperativos em suas aulas. No entanto, este tipo de atividade se restringiu a apenas uma semana de aula. As relações sociais entre a turma e o aluno com SD foram trabalhadas de forma indireta em todos os momentos durante as situações decorrentes da aula. As relações de troca também não foram estimuladas durante o tempo livre. 


\subsection{AmBIENTE}

Não foram observadas quaisquer dificuldades de locomoção e utilização do espaço. $\mathrm{O}$ aluno conseguia transitar livremente pela escola e suas dependências, utilizando seus espaços sem ajuda de colegas ou funcionários da escola. Não foram necessárias adaptações em sua estrutura. A escola apresenta poucas modificações como rampas, barras e faixas em cores contrastantes.

\section{Discussão}

As pesquisas com objetivo de averiguar a contemplação da inclusão de alunos com deficiência nas aulas de educação física auxiliam na compreensão dos seus fatores positivos e negativos relacionados. Este tipo de estudo traz ao pesquisador as possíveis falhas e obstáculos ainda presentes durante esse processo, permitindo que este o reformule ou estabeleça novas estratégias para que o objetivo final da inclusão seja atingido. Aliado a isso, a análise das aulas de educação física como contextos inclusivistas serve como subsídio para a elaboração, concretização e até alterações nas políticas públicas relacionadas com a educação especial.

A observação das aulas de educação física revelou a existência de pontos positivos e negativos para a concretização do processo inclusivo do aluno com SD. Estes resultados demonstram que os objetivos do movimento inclusivo foram atingidos parcialmente. Apesar da ausência de dificuldades de compreensão e execução das atividades propostas, o aluno com SD demonstrou a estruturação de relações sociais limitadas com os colegas de classe. Estas se estabeleceram em maior parte durante a execução das atividades e não durante o tempo livre de aula. Estes resultados estão condizentes com os encontrados por Batista e Enumo (2004); Blinde e McCallister (1998); Ellis, Wright e Cronis (1996); Hutzler et al (2002); e Place e Hodge (2001). No entanto, o não estabelecimento de relações sociais durante o tempo de livre de aula ainda contradiz os achados de Ellis, Wright e Cronis (1996), no qual as relações eram também limitadas, porém predominantes no tempo livre de aula. 
A aprendizagem dos conteúdos propostos, bem como a participação social na turma deveria ser visível no tempo livre da aula. O comportamento de isolamento e não envolvimento em nenhuma das atividades propostas neste período pelos colegas demonstra uma falha na inclusão deste aluno. Neste período deveria ser possível visualizar o aprendizado decorrente das atividades realizadas sob orientação da professora e as relações sociais construídas pelo aluno.

O isolamento social do aluno com SD nesse período de tempo livre não se deve a falta de compreensão ou capacidade para participar das atividades propostas pelos colegas, mas sim da ausência de relações sociais com seus pares. $\mathrm{O}$ isolamento social do aluno com deficiência nas aulas de educação física também foi descrito por Goodwin e Watkinson (2000).

A construção de relações sociais pobres e limitadas pelos alunos com SD revela uma das dificuldades encontradas pelo professor durante o processo inclusivo de seu aluno. A simples adaptação dos conteúdos e atividades para que o aluno com SD consiga participar das atividades propostas em aula não garante que o seu processo inclusivo seja concretizado com sucesso. O processo inclusivo desse aluno deve ir além da oportunidade de atingir as metas educacionais propostas pelo sistema de ensino, proporcionando também a sua inclusão na rede social presente em sua turma e no ambiente escolar como um todo.

Oferecer condições de compreensão e execução das atividades não é suficiente para possibilitar a inclusão do aluno nas aulas de educação física. As adaptações necessárias para concretização do processo inclusivo devem ocorrer em todos os aspectos da aula, com reestruturação do ambiente, objetivos, conteúdos e atividades. A inclusão de alunos com SD nas aulas de educação física deve ter como objetivo claro os benefícios da aprendizagem dos conteúdos escolares, mas também os benefícios da estruturação de relações sociais com seus pares. 
Em estudo realizado por Lienert, Sherril e Myers (2001), os professores de educação física apontam que a inclusão tem como benefício maior para os alunos com e sem deficiência a interação social. Poucos participantes relataram os benefícios da aprendizagem das habilidades motoras. O estudo tinha caráter transcultural e foi realizado com professores de educação física nos Estados Unidos e Alemanha.

A falta de capacitação profissional e infraestrutura escolar são as maiores dificuldades vivenciadas pelos professores para a inclusão. Os professores de educação física assumem possuir pouco ou nenhum conhecimento sobre os tipos de deficiências dos seus alunos (LEONARDO; BRAY; ROSSATO, 2009) e falta de experiência e treinamento inadequado em inclusão (BLOCK; OBRUSNIKOVA, 2007; CHANDLER; GREENE, 1995; KLAVINA; KUDLACEK, 2011; LA MASTER et al, 1998; LIEBERMAN et al, 2002; LIENERT; SHERRIL; MYERS, 2001).

A análise da aula de educação física para alunos com deficiência demonstra que a inclusão do aluno com SD ainda é falha. A inclusão do mesmo esbarra em dificuldades severas para promover a sua participação social junto à turma. No entanto, estes resultados não devem ser generalizados, pois o estudo apresenta algumas limitações. Dentre estas podemos citar a delimitação do estudo em um estudo de caso do aluno com SD, resultando em pouca diversidade das dificuldades e limitações encontradas na realidade escolar. A realidade escolar abrange alunos com diferentes tipos e graus de deficiência. O estudo ainda limitou-se apenas a uma unidade escolar do ensino fundamental. Para a avaliação do processo inclusivo teria sido de grande valia a realização de entrevistas com o próprio aluno com deficiência para compreensão dos pontos positivos e negativos vivenciados por este. É importante ressaltar que os métodos utilizados para tal não foram capazes de elucidar com a devida clareza as possíveis causas para a ocorrência das restrições presentes no processo inclusivo desses alunos. 
Para melhor elucidação das dificuldades encontradas durante o processo inclusivo de alunos com deficiência é importante que sejam ouvidos os próprios alunos e seus pais (GOODWIN; WATKINSON, 2000; COOK; SWAIN; FRENCH, 2001; PIVIK; MCCOMAS, 2002; HUTZLER et al, 2002). Outro ponto importante para a não concretização do processo inclusivo é falta de conhecimento do professor para trabalhar com alunos com deficiência (ROLL-PETTERSON, 2001; HUTZLER et al, 2002; PIVIK; MCCOMAS; LAFLAME, 2002; BLOCK; OBRUSNIKOVA, 2007). Essa falta de conhecimento geralmente faz com o que o professor tenha uma visão negativa sobre o processo e acabe criando experiências negativas para o seu aluno (BLOCK; OBRUSNIKOVA, 2007). O processo inclusivo pode ter sucesso e não causar prejuízos para seus alunos desde que os alunos com deficiência recebam o devido suporte material e profissional especializado (BLOCK; ZEMAN, 1996; PLACE; HODGE, 2001; BLOCK; OBRUSNIKOVA, 2007).

Os resultados aqui relatados demonstram que há ainda muitas lacunas a serem preenchidas a respeito do processo inclusivo de alunos com deficiência. São poucos os estudos que procuram investigar a concretização do processo inclusivo desses alunos na rede regular de ensino a partir da análise da sua participação efetiva e aprendizagem dos conteúdos propostos, bem como a construção de relações sociais. Futuros estudos devem analisar as causas das limitadas relações sociais estruturadas pela criança com deficiência durante as aulas de educação física. Estudos semelhantes a este devem ser realizados com um número maior de alunos com deficiência como sujeitos, analisando o processo inclusivo em diversas escolas e em diferentes regiões brasileiras. Dessa forma, poderão ser observados e elucidados as possíveis falhas presentes no sistema educacional brasileiro para a concretização da inclusão de alunos com deficiência. Tal elucidação é de fundamental importância para alteração e elaboração de novas políticas públicas para melhoria do processo inclusivo. 


\section{The Participation of Students with Down Syndrome in Physical Education Classes: a Case Study \\ Abstract: The objective of this study was to observe real-world inclusion of children with Down Syndrome (SD) in physical education classes in school. Furthermore, we identified possible hindering and facilitating factors during classes. This analysis was performed through systematic observation of physical education classes during the school year. Thirty-three (20 boys and 13 girls) 3rd grade students and one nine years old boy with SD served as subjects for this study. The student with SD did not show difficulties in understanding and performing activities during practice. However, he did not easily establish social relationships with his peers.}

Keywords: Down syndrome. Physical Education, equity. Lectures.

\section{La Participación de los Estudiantes con Síndrome de Down en las Clases de Educación Física: Un estudio de Caso \\ Resumen: El objetivo del estudio fue observar la realidad de la inclusión de los niños con síndrome de Down (SD) en clases de educación física con la identificación de obstáculos y facilidades encontradas. Se realizó la observación sistemática de las clases de educación física durante el año escolar. Los participantes fueron 33 (20 niños y 13 niñas) estudiantes de la tercera serie sin discapacidades y uno estudiante con SD del sexo masculino y con nueve años de edad. El estudiante con SD tenía dificultades para participar socialmente con el grupo, aunque no presentó dificultades en la comprensión y ejecución de las actividades propuestas en el aula. \\ Palabras- clave: Síndrome de Down. Educación Física, equidad. Clases.}




\section{REFERÊNCIAS}

ALVES, Maria Luíza Tanure; DUARTE, Edison. Os caminhos percorridos pelo processo inclusivo de alunos com deficiência na escola: uma reflexão dos direitos construídos historicamente. Revista Educação Especial, Santa Maria, v. 24, n. 40, p. 207-218, maio/ago, 2011.

BATISTA, Marcus Welby; ENUMO, Sônia Regina Fiorim. Inclusão Escolar e Deficiência Mental: Análise da Interação Social entre Companheiros. Estudos de Psicologia, Natal, v. 9, n. 1, p.101-111, 2004.

BLINDE, Elaine; McCALLISTER, Sara. Listening to te Voices of students with Physical Disabilities. Journal of Physical Education, Recreation and Dance, Virginia,v. 69, n.6, p.64-68, 1998.

BLOCK, Martin; OBRUSNIKOVA, Iva. Inclusion in Physical Education: A Review of Literature from 1995-2005. Adapted Physical Activity Quartely, Illinois, v. 24, p. 103-124, 2007.

BLOCK, Martin; ZEMAN, Ron. Including students with disabilities in regular physical education: effects on nondisabled children. Adapted Physical Activity Quartely, Illinois,v. 13, n.1, p.38-49, 1996.

BRASIL. Declaração de Salamanca e Linha de Ação sobre Necessidades Educativas Especiais. Brasília: UNESCO, 1994.

Brasil. [Decreto Legislativo no 186 de 9 julho de 2008]. Aprova o texto da Convenção sobre os Direitos das Pessoas com Deficiência e de seu Protocolo Facultativo, assinados em Nova lorque, em 30 de março de 2007. Diário Oficial da União, Brasília DF, 10 jul. 2008a. Seção 1, Edição 131, p. 1.

BRASIL. Ministério da Educação. Secretaria de Educação Especial. Política Nacional de Educação Especial na Perspectiva da Educação Inclusiva. Documento elaborado pelo Grupo de Trabalho nomeado pela Portaria Ministerial oㅡ 555, de 5 de junho de 2007, prorrogada pela Portaria no 948, de 09 de outubro de 2007. Brasília, DF. MEC/SEESP, 2008. Disponível em : <http://portal.mec.gov.br/arquivos/pdf/ politicaeducespecial.pdf.>. Acesso em : 11 de jan 2012.

CHANDLER, Judy; GREENE, J.Leon. A Statewide Survey of adapted Physical education Service Delivery and Teacher In-service Training. Adapted Physical Activity Quartely, Illinois, v. 15, p. 370-380, 1995.

COOK, Tina; SWAIN, John; FRENCH, Sally. Voices from Segregated Schooling: Towards an Inclusive Education System. Disability and Society, Newcastle, v.16, n. 2, p. 293-310, 2001. 
ELLIS, David; WRIGHT, Margaret; CRONIS, Terry. A Description of the Instructional and Social Interactions of Students with Mental Retardation in Regular Physical Educations Settings. Education and Training in Mental Retardation and Developmental Disabilities, Arlington, v.31, Sept., p. 235-241, 1996.

GOODWIN, Donna; WATKINSON, Jane. Inclusive Physical Education from the Perspective of Students with Physical Disabilities. Adapted Physical Activity Quartely, Illinois, v. 17, p. 144-163, 2000.

HUTZLER, Yesahayu.; FLIESS, Osnat; CHACHAM, Anat; AUWEELE, Yves Van den. Perspectives of Children with Disabilities on Inclusion and Empowerment: Supporting and Limiting factors. Adapted Physical Activity Quartely, Illinois, v. 19, p. 300317, 2002.

KLAVINA, Aija; KUDLACEK, Martin. Physical Education for Students with Special Education Needs in Europe: Findings of the Eusapa Project. European Journal of Adapted Physical Activity, Olomouc, v.4,n. 2, p. 46-62, 2011.

KODISH, Stephen; KULINNA, Pamela Hodges; MARTIN, Jeffrey; PANGRAZI, Robert; DARST, Paul. Determinants of Physical Activity in an Inclusive Setting. Adapted Physical Activity Quartely, Illinois, v. 23, p. 390-409, 2006.

LA MASTER, Kathryn; GALL, Kimerly; KINCHIN, Gary; SIEDENTOP, Daryl. Inclusion Pratices of Effective Elementary Specialists. Adapted Physical Activity Quartely,Illinois, v. 15, p. 64-81, 1998.

LEONARDO, Nilza Sanches Tessaro; BRAY, Cristiane Toller; ROSSATO, Solange Pereira Marques. Inclusão Escolar: Um Estudo Acerca da Implantação da Proposta em Escolas de Ensino Básico. Revista Brasileira de Educação Especial, Marília, v.15, n.2, p. 289-306, 2009.

LIEBERMAN, Lauren; HOUSTON- WILSON, Cathy; KOZUB, Francis. Perceived Barriers to Including Students with Visual Impairments in General Physical Education. Adapted Physical Activity Quartely, Illinois, v. 19,p. 364-377, 2002.

LIENERT, Christoph; SHERRIL, Claudine; MYERS, Bettye. Physical Educators' Concerns About Integrating Children With Disabilities:A Cross-Cultural Comparison, Adapted Physical Activity Quartely, Illinois, v. 18, p.1-17, 2001.

ODOM, Samuel; DIAMOND, Karen; Inclusion of Young Children with Special Needs in Early Childhood Education: The Research Base. Early Childhood Research Quartely, Fairfax, v. 13, n.1, p.3-25, 1998.

PIVIK, Jayne; MCCOMAS, Joan; LAFLAME, Marc. Barriers and Facilitators to Inclusive Education. Exceptional Children, Arlington, v. 69, n. 1, p.97-107, 2002. 
PLACE, Kimberly.; HODGE, Samuel. Social Inclusion of Students with Psysical Disabilities in General Physical Education: A Behavioral Analyses. Adapted Physical Activity Quartely, Illinois, v. 18, p.389-404, 2001.

ROLL-PETTERSON, Lise. Teacher Perceptions of Supports and Resources Deficiênciaded in Regard to Pupils with Special education Deficiênciads in Sweden. Education and Training in Mental Retardation and Developmental Disabilities, Arlington, v. 36, no.1, p.42-54, 2001.

Endereço para correspondência:

Maria Luíza Tanure Alves

Rua José Antônio Marinho, 297 Sta Genebra II

Campinas- SP CEP 13084783

Recebido em:20.04.2012

Aprovado em: 8.8.2012 
